\title{
Subacute necrotizing encephalopathy in an acidotic child
}

\author{
PETER G. PROCOPIS, BRIAN TURNER, AND GEORGE SELBY \\ From the Oliver Latham Laboratory, Psychiatric Centre, North Ryde, and \\ The Royal North Shore Hospital of Sydney, New South Wales, Australia
}

Subacute necrotizing encephalopathy was described originally by Leigh (1951). Further case reports reviewed by Ebels, Blokzijl, and Troelstra (1965) have confirmed this condition as a neuropathological entity but ideas concerning its aetiology have remained speculative. Recently Worsley, Brookfield, Elwood, Noble, and Taylor (1965) have reported a case, with confirmation at necropsy, in which there was a persistent lactic acidosis during life. A sibling had died of a similar illness. The authors postulated a disturbance of lactic acid metabolism in this disease.

The present report describes a patient with infantile subacute necrotizing encephalopathy in whom a persistent acidosis was a feature of the illness during life.

\section{CASE REPORT}

The patient was born on 23 December 1961 after a normal pregnancy and labour. His older sister was normal and the only family history of nervous disease was in a cousin of his mother, who was said to have suffered from poliomyelitis and encephalitis.

In the period from 4 July 1963 to 10 February 1964 he was treated at another hospital for intermittent attacks of vomiting and failure to thrive, necessitating three admissions to hospital for a period of about one month each. At the time of his first admission to hospital no abnormal physical signs were present, but in August 1963 he was noted to have a slightly ataxic gait.

Investigations showed a persistently raised protein level in the cerebrospinal fluid of the order of $100 \mathrm{mg}$./ $100 \mathrm{ml}$. but no increase in cells. Pneumoencephalograms performed in July 1963, in September 1963, and in January 1964, and a ventriculogram in January 1964 were all normal. Electroencephalograms were at first normal, but in September 1963 and in January 1964 showed an excess of slow wave activity with no focal abnormalities. In February 1964, however, the electroencephalogram showed marked improvement and was considered to be within normal limits. The serum electrolytes, blood urea, urinary 17-ketosteroids, urinary coproporphyrins, haemoglobin, blood sedimentation rate, and serum phenylalanine were all normal. Radio- graphs of the chest, abdomen, skull, hands, wrists, and knees showed no abnormality.

On 13 February 1964 he was admitted to the Royal North Shore Hospital of Sydney at the age of 2 years 2 months for further investigation of vomiting. His weight was $10.6 \mathrm{~kg}$., temperature $37^{\circ} \mathrm{C}$., and pulse rate 140 per minute. The limbs were hypotonic, gait was ataxic, and reflexes were slightly diminished. No nystagmus was present and the optic discs were normal. Other systems showed no abnormality.

Electroencephalograms and skull radiographs were normal, haemoglobin was $12.3 \mathrm{~g} . / 100 \mathrm{ml}$., white cell count was $6,100 / \mathrm{c} . \mathrm{mm}$. with a normal differential count, and examination of the stained blood film was normal.

Over the next 12 months no further vomiting occurred, but the ataxia slowly progressed and by February 1965 he could no longer walk unaided. No fits or headaches had occurred and he was still unable to speak.

He was readmitted on 21 April 1965 with a history of cough and laboured breathing for seven days.

The temperature was $38^{\circ} \mathrm{C}$., respiratory rate 42 per minute, and pulse rate 120 per minute. The tonsils were inflamed and loud rales were present over both lung fields. Gait was very ataxic, although the hands were fairly coordinate. The optic fundi were normal, the reflexes were sluggish and the plantar responses flexor. No nystagmus was present.

Lumbar puncture revealed clear fluid at a pressure of $100 \mathrm{~mm}$. of cerebrospinal fluid. The protein was $100 \mathrm{mg}$./ $100 \mathrm{ml}$. and sugar $120 \mathrm{mg} . / 100 \mathrm{ml}$. The cerebrospinal fluid was sterile on culture and no acid-fast bacilli or Torula were demonstrated. The haemoglobin was $13.6 \mathrm{~g} . / 100 \mathrm{ml}$. and white cell count $65,000 / \mathrm{c} . \mathrm{mm}$. with $83 \%$ neutrophils. The serum sodium level was $138 \mathrm{mEq} . / \mathrm{l}$., potassium level $4.9 \mathrm{mEq} . / 1$., blood urea level $45 \mathrm{mg} . / 100 \mathrm{ml}$, calcium level $9.7 \mathrm{mg} . / 100 \mathrm{ml}$, phosphorus level $4.4 \mathrm{mg} . / 100 \mathrm{ml}$., alkaline phosphatase 6.6 King-Armstrong units, and blood sugar level $105 \mathrm{mg} . / 100 \mathrm{ml}$. The urine was acid in reaction and contained no ketones or reducing substances. The urinary aminoacid chromatogram was normal. A radiograph of the chest showed an opacity at the apex of the left lower lobe and consolidation in the posterior basal segment. An intravenous pyelogram was normal.

On the day of admission the arterial carbon dioxide tension was $17 \mathrm{~mm}$. of mercury, standard bicarbonate 349 
$13.4 \mathrm{mEq} . / \mathrm{l}$, and blood $p \mathrm{H}$ 7.33. On 23 April the carbon dioxide tension was $28 \mathrm{~mm}$. of mercury, standard bicarbonate $16.7 \mathrm{mEq}$./1., and blood $p \mathrm{H} 7.34$.

Treatment with intramuscular injections of crystalline penicillin resulted in rapid resolution of the chest infection and both the chest radiograph and white cell count returned to normal. He was discharged on 1 June.

The patient was readmitted on 2 July with a three-day history of fever, vomiting, and hyperventilation. On examination, the temperature was $38 \cdot 2^{\circ} \mathrm{C}$., respiratory rate 52 per minute, pulse rate 120 per minute, and widespread rales were present throughout the chest. He appeared to be more retarded and more ataxic than during the last admission. He showed marked generalized hypotonia and had difficulty in holding his head up. All limbs showed symmetrical cerebellar ataxia. No nystagmus was present. The optic discs were flat, but pale, consistent with some optic atrophy. The pupils were dilated and reacted sluggishly to light, and sight appeared to be poor.

The haemoglobin was $15.6 \mathrm{~g} . / 100 \mathrm{ml}$. and white cell count $10,200 / \mathrm{c} . \mathrm{mm}$. with a normal differential count. The blood urea was $40 \mathrm{mg} . / 100 \mathrm{ml}$., total serum protein $7.2 \mathrm{~g} . / 100$ $\mathrm{ml}$. (albumin $4.7 \mathrm{~g} . / 100 \mathrm{ml}$. and globulin $2.5 \mathrm{~g} . / 100 \mathrm{ml}$.); the electrophoretic pattern was normal. The cerebrospinal fluid was clear and contained no cells, protein was $145 \mathrm{mg} . / 100 \mathrm{ml}$., globulin negative, chloride $765 \mathrm{mg} . / 100$ ml., and sugar $50 \mathrm{mg} . / 100 \mathrm{ml}$; the colloidal mastic reaction was 143311-0 and V.D.R.L. test negative. An electroencephalogram under Seconal sedation showed episodic bilateral 0.5-1 cycle per second delta frequencies of high amplitude, with some focal accentuation from the posterior part of the right hemisphere.

A lumbar pneumoencephalogram showed the right lateral ventricle to be slightly larger than the left. No other abnormality was demonstrated.

After treatment with tetracycline the temperature and chest infection settled although the pulse rate remained persistently above 100 per minute. The serum sodium level was then $139 \mathrm{mEq} . / \mathrm{l}$, potassium $4.7 \mathrm{mEq} . / \mathrm{l}$., chloride $112 \mathrm{mEq}$./1., and bicarbonate, measured with the serum equilibrated to a $\mathrm{pCO}_{2}$ of $40 \mathrm{~mm}$. of mercury, was $17 \mathrm{mEq}$./l. Over the ensuing weeks he was noticed to have attacks lasting three to four days in which he became more ataxic and in which spontaneous horizontal nystagmus appeared, although the chest remained clear and temperature normal. The nystagmus was at first present only during an attack, but after six weeks it became continuous.

In October 1965, he again became listless and vomited. The temperature was normal, pulse rate 140 per minute, and scattered rales were present throughout the chest. He died suddenly in his sleep on 20 October 1965, the terminal illness having lasted for three days.

\section{MORBID ANATOMY}

Necropsy was performed eight hours after death by Dr. K. Viner Smith. Aspiration pneumonia was found; other systems showed no significant abnormality.

The brain was fixed by suspension in formol-saline. On external examination the optic nerves were thinner than normal and the pons was small; no other external abnormalities were apparent. On section of the cerebral hemispheres foci of discolored cystic softening were present bilaterally in the putamen and the central white matter of the parietal and occipital lobes. The white matter throughout was generally firmer than normal. In the brainstem, areas of symmetrical discoloration were present in the habenular nuclei, inferior colliculi, the middle cerebellar peduncles, the superior and inferior olivary nuclei. The cerebellum was shrunken and firm with areas of atrophy of the cortex. Both dentate nuclei showed cystic discoloration. Smaller lesions were also seen in the central white matter of the cerebellum.

\section{HISTOLOGICAL EXAMINATION}

Representative blocks of the brain were embedded in celloidin and sections were stained by routine neuropathological methods. Sections from paraffin-embedded material were also examined.

In the meninges there was a conspicuous dilatation of the veins with little, if any, excess of cells in the subarachnoid space. The cerebral cortex and the hippocampal gyrus showed nor abnormality apart from very occasional shrunken nerve cells. The macroscopic lesions in the central white matter (Fig. 1) showed areas of tissue necrosis with myelin breakdown and compound granular corpuscle formation with intense glial fibre proliferation and with conspicuous dilatation of the blood vessels. Less conspicuous lesions were widespread throughout the central white matter. The earliest lesion appeared to be $a$ 을 perivascular fibrous glial reaction with enlarging areas of tissue necrosis and myelin breakdown with compoundo granular corpuscle formation. In the larger and apparentlyo older lesions gemastate astrocyte formation had occurred. Throughout the white matter there was a general excess of astrocyte nuclei. Similar lesions were present in the optic tract. In the cerebellar white matter a linear area of myelin destruction was present (Fig. 2). The cerebellar cortex showed degenerative changes with loss of Purkinje cells and torpedo formation on the Purkinje axones.

The lesions in the nuclei were similar to those in the white matter but appeared to be characterized by a more intense vascular dilatation and capillary proliferation. Such lesions were seen in the putamen and in the nuclei throughout the brainstem with a tendency toward symmetry. Pallor of myelin staining was prominent in the brainstem, being most marked adjacent to the areas of tissue necrosis (Fig. 3). Despite the severity of the necrosis nerve cells appeared to be spared within the areas of destruction. It is of interest that the mammillary bodies showed no abnormality and that small early lesions were present in the substantia nigra of this case.

The changes were considered to be diagnostic of infantile subacute necrotizing encephalopathy.

\section{DISCUSSION}

Infantile subacute necrotizing encephalopathy is a disease of infancy or early childhood with a progressive, often episodic, course. The earliest symptoms, referable to the brainstem lesions, include muscular 


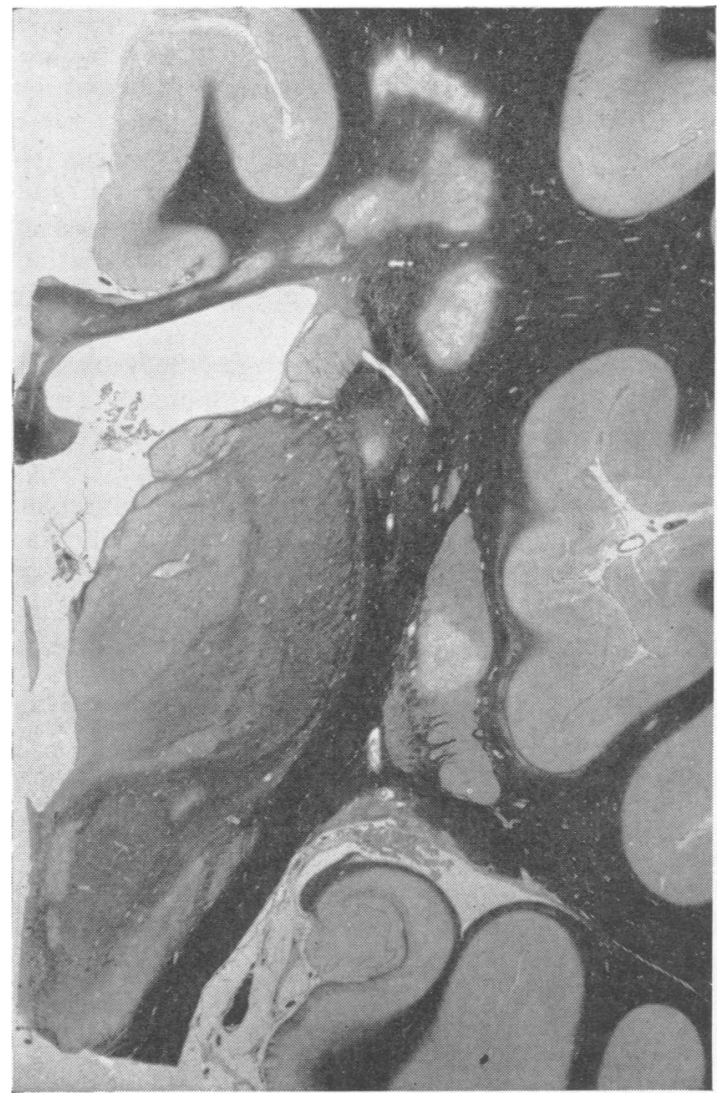

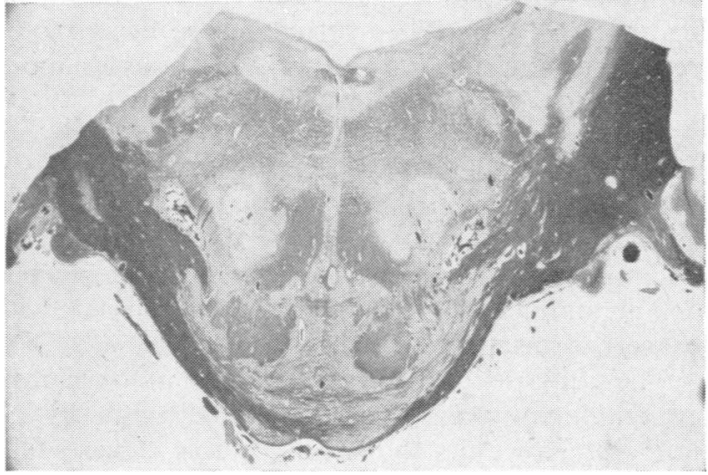

FIG. 3.

FIG. 1. Areas of demyelination in the central semiovale, putamen, corpus callosum and midbrain. Methasol fast blue, actual size.

FIG. 2. Demyelination in the cerebellar white matter and the dentate nucleus. Methasol fast blue, actual size.

FIG. 3. Diffuse demyelination in the pons with symmetrical areas of necrosis and prominent blood vessels. Methasol fast blue $\times 1.75$.

FIG. 1 .

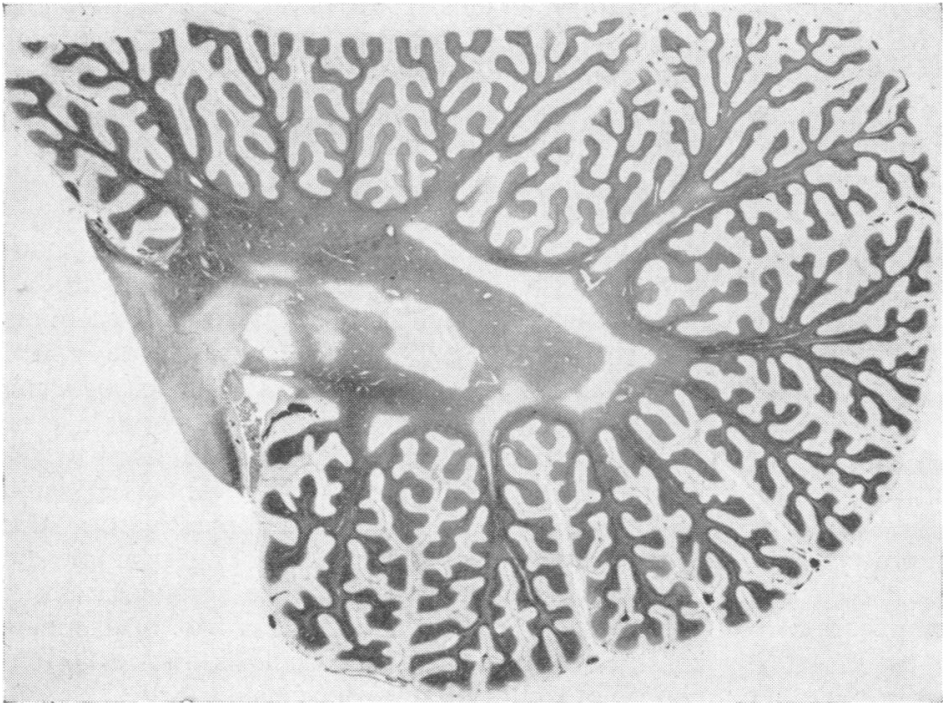

FIG. 2. 
weakness, hypotonia, ataxia, and diminution of the pupillary light reflex. The duration of the disease is variable; some patients have survived into the second decade. A familial incidence has been noted repeatedly and suggests an autosomal recessive mode of inheritance.

In the present case a feature of the illness, not recorded in previously published cases, was a persistent and unexplained tachycardia. The heart rate rarely fell below 100 per minute in eight months and there were repeated episodes when it reached 140 per minute. This did not appear to correlate with exacerbations of the neurological illness.

The similarity of the lesions to those of Wernicke's encephalopathy has been remarked upon by all authors. However, the brunt of this disease falls upon the brainstem rather than upon the mammillary body and the hypothalamus as in Wernicke's encephalopathy. In subacute necrotizing encephalopathy the mammillary bodies are usually spared and the substantia nigra is often involved in contradistinction to Wernicke's encephalopathy.

The familial incidence of necrotizing encephalopathy has led many authors to postulate that it represents an inborn error of metabolism, though the site of the metabolic defect has escaped detection. Recently Worsley and her colleagues (1965) have reported a patient subsequently proved to have infantile subacute necrotizing encephalopathy. Attacks of spontaneous hyperventilation led them to detect a persistent metabolic acidosis and an elevation of plasma lactate and pyruvate levels during the course of the illness. Studies in vitro of the formation of lactate by the patient's red cells suggested that lactate was produced more rapidly than in normal controls.

In the present case, attacks of hyperventilation and a persistent metabolic acidosis of undetermined origin were features of the last six months of the illness. Although plasma lactate levels were not measured metabolic acidosis was clearly shown in April 1965 by blood gas analysis. In July 1965, after a chest infection had settled, an equilibrated bicarbonate reading remained at an acidotic level. Serum electrolyte estimations showed a normal potassium level, in spite of acidosis, and a raised chloride level. Similar results were obtained by Worsley et al. from their two cases of necrotizing encephalopathy and they attribute the hyperchloraemia to the inability of the kidneys to cope with the anionic load. In the other reported cases acidosis has been described only in case 1 of Feigin and Wolf (1954), in a personal communication to Worsley, and in the cases described by Worsley. Mention has not been made of acidosis in the other published cases.
Worsley et al. (1965) postulate an inborn error of metabolism resulting in the production of excess lactate as the basis of this disease. It remains speculative as to how this produces the characteristic brainstem and other lesions, but the similarity to Wernicke's encephalopathy where pyruvate and lactate levels are also raised is striking. In cases of infantile subacute necrotizing encephalopathy no aneurine deficiency has been demonstrated (Ebels et al., 1965).

In the patient of Worsley et al. (1965) plasma lactate and pyruvate levels were increased proportionately, so that their normal ratio was maintained. Such increases in pyruvate and lactate levels are found following strenuous muscular exercise, in aneurine deficiency and hypocapnia, and differ from the cases of 'primary' lactic acidosis described by Huckabee (1961) and from cases where there is severe hypoxia or shock, in which there is an excess of lactate over pyruvate.

Consideration must also be given to the concept of 'central neurogenic hyperventilation'. Plum and Swanson (1959) showed that lesions of the medial pontine tegmentum are associated with hyperventilation and postulated that the lesion prevented inhibitory impulses descending to the respiratory centres in the medulla. The involvement of the pontine reticular formation in these patients would explain the hyperventilation in the patients with necrotizing encephalopathy, although a respiratory alkalosis rather than a metabolic acidosis would be expected to occur. Primary hyperventilation causes a decrease in alveolar and hence arterial carbon dioxide tension and a consequent rise in blood $p H$ (respiratory alkalosis). However, after a time the blood $p \mathrm{H}$ returns to normal despite the presence of a lowered carbon dioxide tension. This restoration of the $p \mathrm{H}$ requires a deficit in bicarbonate ion to restore the Henderson-Hasselbach ratio to normal. Previously it was thought that compensation occurred by decreased renal tubular secretion of hydrogen ion and increased bicarbonate concentration in the urine. However, recent studies have shown that renal loss of bicarbonate accounts only for about $5 \%$ of the bicarbonate deficit (Eichenholz, 1965), and most of that deficit by a rise in lactic and pyruvic acids causing bicarbonate to be converted to carbonic acid which is excreted by the lungs (Eichenholz, Mulhausen, Anderson, and MacDonald, 1962). The same investigators also showed that the continued loss of bicarbonate did not end at the stage of complete compensation. If hypocapnia was sustained, loss of bicarbonate continued and a metabolic acidosis due to accumulation of lactic and pyruvic acids resulted.

The present case supports the observations of 
Worsley et al. (1965) of acidosis in patients with infantile subacute necrotizing encephalopathy. It remains for the study of further cases to determine whether an acidosis is a feature of all cases and to discover the nature of the relationship between acidosis and the observed neuropathological lesions.

\section{SUMMARY}

A case of subacute necrotizing encephalopathy associated with an acidosis is described. This observation supports the previously reported association between acidosis and this disease.

We wish to acknowledge Dr. K. Viner Smith who kindly made the specimen and his reports available, Dr. June Raine for biochemical estimations, and Mr. V. C. Conlay for his photographic and histological preparations. We thank the Director, Division of Establishments, New
South Wales Department of Public Health, and the General Superintendent, Royal North Shore Hospital, for their permission to publish this account.

\section{REFERENCES}

Ebels, E. J., Blokzijl, E. J., and Troelstra, J. A. (1965). A Wernicke-like encephalomyelopathy in children (Leigh), an inborn error of metabolism? Helv. Paediat. Acta, 20, 310-324.

Eichenholz, A. (1965). Respiratory alkalosis. Arch. intern. Med., 116, 699-708.

-, Mulhausen, R. O., Anderson, W. E., and MacDonald, F. M. (1962). Primary hypocapnia: A cause of metabolic acidosis. J. appl. Physiol., 17, 283-288.

Feigin, I., and Wolf, A. (1954). A disease in infants resembling cirronic Wernicke's encephalopathy. J. Pediat., 45, 243-263.

Huckabee, W. E. (1961). Abnormal resting blood lactate. II. Lactic acidosis. Amer. J. Med., 30, 840-848.

Leigh, D. J. (1951). Subacute necrotising encephalomyelopathy in an infant. J. Neurol. Neurosurg. Psychiat., 14, 216-221.

Plum, F., and Swanson, A. G. (1959). Central neurogenic hyperventilation in man. Arch. Neurol. Psychiat. (Chic.), 81, 535-549.

Worsley, H. E., Brookfield, R. W., Elwood, J. S., Noble, R. L., and Taylor, W. H. (1965). Lactic acidosis with necrotizing encephalopathy in two sibs. Arch. Dis. Childh., 40, 492-501. 